\title{
autêntica
}

ARTIGOS

\section{A FORMAÇÃO DE PROFESSORES PARA A EDUCAÇÃO INCLUSIVA DE ALUNOS COM DEFICIÊNCIAS A PARTIR DA LITERATURA}

Suelen Aparecida FELICETTI

Universidade Estadual do Paraná, UEL

Londrina, Paraná, Brasil

Suelen_jv.80@hotmail.com

ORCID https://orcid.org/0000-0003-1260-4154

Irinea de Lourdes BATISTA

Universidade Estadual de Londrina - UEL

Londrina, Paraná, Brasil

irinea@uel.br

ORCID https://orcid.org 0000-0001-8690-2344

\begin{abstract}
Resumo: Os professores de diferentes níveis de ensino nem sempre estão preparados para lidar com as especificidades de aprendizagem evidenciadas na Educação Inclusiva (EI) de alunos com deficiências. A compreensão desta afirmação leva a questionar: como acontecem as discussões dos processos de formação inicial e em serviço com os professores voltados à educação por esta perspectiva? Para responder à problemática objetivou-se compreender, com base na literatura, como está sendo discutida a formação docente voltada à El de alunos com deficiências. Realizou-se uma revisão da literatura a respeito da formação por esta perspectiva, a qual forneceu materiais para abordar algumas tendências, relacionadas com a compreensão de El, os objetivos da formação, orientações para tal procedimento e dificuldades encontradas. Evidenciou-se que existe preocupação em formar professores pra consolidar a inclusão, ação que representa uma maneira de fortalecê-la frente aos alunos com deficiências.
\end{abstract}

Palavras-chave: Educação Inclusiva. Formação de professores. Deficiências. 


\title{
TEACHER TRAINING FOR THE INCLUSIVE EDUCATION OF DISABILITIES STUDENTS BASED ON LITERATURE
}

\begin{abstract}
Teachers of different levels of education are not always prepared to deal, with learning' specificities evidenced in Inclusive Education (IE) of students with disabilities. The understanding of this statement leads to the question: how take place with teachers participating of initial and in-service training processes, discussions focused on education from this perspective? In order to respond to the problem, the objective was to understand, based on the literature, how is being discussed the teacher education, focused in the students with disabilities' IE. A literature review was realized, regarding teachers' training from this perspective, which provided materials to address some trends, related to the understanding of El, the objectives of training, orientations for this procedure and difficulties founded. It became evident, that there is a concern with teachers training to consolidate the inclusion, an action that represents a way to fortify it in the face of disabilities students.
\end{abstract}

Keywords: Inclusive Education. teachers training. disabilities.

\section{FORMACIÓN DE PROFESORES PARA LA EDUCACIÓN INCLUSIVA DE ESTUDIANTES CON DISCAPACIDAD BASADO EN LITERATURA}

Resumen: Los docentes de diferentes niveles de educación no siempre están preparados para lidiar con las especificidades de aprendizaje evidenciadas en la Educación Inclusiva (IE) de estudiantes con discapacidades. La comprensión de esta declaración lleva a la pregunta: ¿cómo se llevan a cabo las discusiones de los procesos de capacitación inicial y en servicio con los docentes centrados en la educación desde esta perspectiva? Con el fin de responder al problema, el objetivo era comprender, en base a la literatura, cómo se está discutiendo la educación docente centrada en la IE de los estudiantes con discapacidades. Se realizó una revisión de la literatura con respecto a la capacitación desde esta perspectiva, que proporcionó materiales para abordar algunas tendencias, relacionadas con la comprensión de la IE, los objetivos de la capacitación, las pautas para dicho procedimiento y las dificultades encontradas. Se hizo evidente que existe una preocupación con la capacitación de maestros para consolidar la inclusión, una acción que representa una forma de fortalecerla frente a los estudiantes con discapacidades.

Palabras-clave: Educación inclusiva. formación de profesores. deficiencias. 


\section{autêntica}

DOI https://doi.org/10.31639/rbpfp.v12i24.312

\section{Introdução}

A inclusão social pressupõe que as diferentes identidades de uma cultura e o potencial dos indivíduos em sua singularidade, sejam reconhecidas e valorizadas, respeitando-se seus direitos e deveres (ESCUDERO; MARTÍNEZ, 2011). Todos eles têm direito de serem incluídos na sociedade e dela usufruírem, independente da sua raça, religião, condição financeira, grau de instrução ou condição física e mental. As pessoas com deficiências fazem parte desse grupo com direito a inclusão.

Um dos direitos assegurados aos sujeitos é a El em nível formal, a qual pressupõe respeitar as diferenças como pontos chave na promoção do ensino e aprendizagem (AINSCOW, 2009). A partir dessa proposta, as escolas se encontram frente ao desafio de desenvolver uma pedagogia capaz de educar com êxito a todos os alunos, inclusive àquelas com deficiências. Precisam desenvolver, implementar, incentivar, acompanhar e avaliar o sistema educacional inclusivo em todos os níveis e modalidades, bem como elaborar currículos considerando as especificidades dos indivíduos (MANTOAN, 2006).

Estas e outras responsabilidades permanecem por vezes confusas quanto a quais ações precisam ser realizadas para que as políticas avancem e como fazer isso, o que torna a El ainda um desafio (AINSCOW, 2009). São necessárias estratégias para superar estes entraves, entre as quais contribui a existência de professores comprometidos com o processo inclusivo de ensino e aprendizagem, o que pode ser favorecidos se eles tiverem acesso a processos formativos em El. Para Nóvoa (1992) a formação oferece tempos e espaços para refletir a prática docente e assimilar conhecimentos científicos e pedagógicos.

Diante da representatividade da formação para a concretização da El de alunos com deficiências surgiu o seguinte questionamento: acontecem as discussões da formação inicial e em serviço de professores voltados à EI? O objetivo principal foi compreender com base na literatura, como está sendo discutida a formação dos referidos professores dentro da temática. A metodologia foi uma revisão da literatura a respeito do tema, a qual permitiu realizar algumas discussões de como os professores estão sendo formados para a El de alunos com deficiências.

\section{Fundamentação teórica}

A inclusão direciona-se a todas as pessoas da sociedade entre as quais estão os sujeitos que sofreram ou sofrem privação ou exclusão dos direitos por conta de alguma particularidade de ordem física ou social, como: crianças pobres, minorias étnicas ou religiosas, requerentes de asilo, sujeitos com deficiências, pessoas doentes, famílias em desvantagem econômica, social e cultural e com dificuldades escolares (ESCUDERO; MARTÍNEZ, 2011).

Fazendo um recorte do público-alvo da inclusão, estão as pessoas com deficiências, compreendidas como aquelas que têm impedimentos de caráter físico, mental, intelectual e sensorial, que, quando interagem com barreiras econômicas, culturais, tecnológicas, políticas, arquitetônicas, comunicacionais, são prejudicadas, podendo até ser discriminadas e excluídas da participação ativa em sociedade. Muitas vezes, elas são alvos de atitudes discriminatórias com a intenção de excluir, diferenciar ou restringir seus direitos (FONSECA, 2012). Este é um possível entendimento, assim como outros poderiam ser aqui discutidos.

A inclusão dos sujeitos desse grupo garante o direito à El, compreendida como aquela que defende a heterogeneidade na classe escolar enquanto situação provocadora de interações entre alunos com características 


\section{autêntica}

DOI https://doi.org/10.31639/rbpfp.v12i24.312

pessoais diversas, interações estas imprescindíveis para fomentar aprendizagens recíprocas (BEYER, 2006). Este tipo de educação é uma questão de direitos humanos, pois não se pode discriminar nenhuma pessoa como consequência de suas particularidades, e uma atitude representante de um sistema de valores e de crenças que quando assumidos em uma escola ou sistema de ensino, tem a obrigação de condicionar decisões e ações daqueles que a tenham adotado (SANCHÉZ, 2005).

Mesmo que a El das pessoas com deficiências seja um direito, não acontece satisfatoriamente por diversas razões, entre as quais a falta de profissionais capacitados, a ausência de parcerias entre profissionais do ensino regular e da Educação Especial e a precariedade de comunicação entre os indivíduos (SOUZA, 2013). Outros fatores prejudiciais se referem: à tentativa de estabelecer um tipo de padrão para a aprendizagem dos alunos; à falta de acompanhamento e comunicação da equipe pedagógica com os professores quanto às necessidades dos alunos; e à atribuição da responsabilidade pela mediação das atividades didático pedagógicas aos serviços de atendimento especializado (RODRIGUES, 2005; NUNES, 2014).

Diante disso, o papel da escola passa a ser o de proporcionar uma formação crítica, autônoma, participativa e cidadã para todos os alunos, de forma que as pessoas com deficiências sejam reconhecidas como possuidoras de capacidade de exercer a cidadania. Entre os princípios adotados está a inclusão como um direito, a valoração dos alunos em sua singularidade, a busca de um ensino de qualidade, o incentivo ao trabalho em equipe, etc. Faz-se necessário a adaptação aos alunos que nela adentram, reconhecendo que cada um aprende de uma forma e com um ritmo próprio, fazendo as adequações necessárias do currículo (HEREDERO, 2010).

Os professores assumem papeis representativos, dentre os quais o de conhecer os alunos com deficiência em suas caraterísticas para notar possíveis demandas decorrentes delas e pensar em estratégias de ensino que possam ser eficientes para promover a aprendizagem (BAZON et. al., 2015). Tal função demanda conhecimentos de diferentes ordens - científicos e os pedagógicos (NÓVOA, 1992), e aqueles das deficiências (BARROS; OLIVEIRA, 2013).

Contribuem para que os professores assimilem estes saberes e produzam os seus próprios, a formação docente, compreendida como qualquer intenção sistemática de melhorar a prática profissional, crenças e conhecimentos profissionais, com o objetivo de aumentar a qualidade docente, de pesquisa e de gestão. Está incluso o diagnóstico de carências atuais e futuras dos professores, o desenvolvimento de políticas, programas e atividades para a satisfação dessas necessidades profissionais (IMBERNÓN, 2002). Ela pode acontecer em nível inicial, nas instituições de ensino superior, voltadas para áreas do conhecimento, ou em serviço, por meio de cursos de preparação contínuos ou pontuais.

Quando se refere a El, não se pode negar que "ocorreram avanços importantes em relação à formação de professores no Brasil, não apenas em termos de legislação, mas também em relação à produção do conhecimento acadêmico voltado para o tema" (PLETSCH, 2009, p. 144). Contudo, ainda existem carências na formação docente nessa perspectiva. Os cursos de graduação não preparam suficientemente para a El, tampouco os cursos de formação em serviço. Nem mesmo os professores que tiveram algum componente curricular com esse enfoque durante a graduação encontram-se adequadamente preparados (VITALIANO; VALENTE, 2010). Rodrigues (2005) afirma que muitos processos formativos não desenvolvem a área das deficiências ou mesmo à omitem; quando a omissão não acontece, são especificados casos de tão severos que podem desmotivar a inclusão, ao invés de motivar.

Desta forma, a formação é um dos aspectos a serem aprimorados para que a inclusão seja concretizada com qualidade (VITALIANO; VALENTE, 2010). Trata-se de um direito que os docentes têm, que deve estruturar-se 


\section{autêntica}

a fim de possibilitar o desenvolvimento pessoal e profissional, como alicerce na escolha e na efetivação de práticas metodológicas adequadas para atender a diversidade de aprendizagem dos alunos (MINETTO, 2008). Os professores têm interesse na área e reconhecem sua relevância no desenvolvimento profissional, o que reforça a representatividade dos processos formativos voltados à inclusão.

\section{Metodologia}

O objetivo principal desta pesquisa foi compreender com base na literatura como está sendo discutida a formação docente para a El de alunos com deficiências. Especificamente buscou-se trazer elementos teóricos para a compreensão das deficiências e da formação de professores nesse contexto.

Foi realizada uma revisão da literatura em periódicos do Brasil a respeito da formação docente para a El de alunos com deficiências. Foram acessadas as revistas da área de Ensino classificadas pela Coordenação de Aperfeiçoamento de Pessoal de Nível Superior (Capes) com Qualis A1, A2 e B1, e pesquisados artigos que fizessem menção ao tema (formação docente para a El de alunos com deficiências). Aqueles cujo título e resumo evidenciaram relação com a temática pesquisada, foram selecionados e analisados minuciosamente.

Assim, na fase inicial os artigos a serem analisados foram escolhidos, na sequência, explorados e analisados e, por último, serviram de base para comunicar uma compreensão geral da literatura acerca da temática. As discussões colocadas nos documentos acerca da formação docente para a El de alunos com deficiências demonstraram tendências, que foram discutidas nos resultados aqui apresentados.

Por fim, destaca-se que, seguindo os critérios de classificação de pesquisas propostos por Gil (2002), está é uma pesquisa bibliográfica, a qual foi desenvolvida com base em materiais já elaborados - artigos científicos. Também, a pesquisa se classifica como qualitativa segundo os pressupostos de Bogdan e Biklen (1994), não buscando qualquer tipo de quantificação. A presença ou ausência se tornam representativas ao invés de quantidade.

\section{Resultados e discussões}

Antes de escrever outras considerações, com o intuito de situar o leitor, as 9 pesquisas analisadas na revisão da literatura foram colocadas no Quadro 1. Apresenta-se uma síntese de cada artigo, o título, autores e ano de publicação. 


\section{autêntica}

\section{Quadro 1: Artigos analisados na revisão da literatura}

\begin{tabular}{|c|c|c|}
\hline Título & Autor(es) Ano & Principais ideias \\
\hline $\begin{array}{l}\text { A formação de } \\
\text { professores para } \\
\text { a El: legislação, } \\
\text { diretrizes políticas } \\
\text { e resultados de } \\
\text { pesquisas }\end{array}$ & $\begin{array}{l}\text { Pletsch } \\
\text { (2009) }\end{array}$ & $\begin{array}{c}\text { A autora faz o levantamento e discussões a respeito da formação } \\
\text { de professores no Brasil, com ênfase na inclusão de pessoas } \\
\text { com deficiências. Utilizou-se como referência a legislação } \\
\text { nacional e as diretrizes políticas específicas do Ministério da } \\
\text { Educação (MEC), e pesquisas já realizadas e publicadas. A } \\
\text { formação docente foi apontada como tradicional, não suprindo } \\
\text { as reivindicações em favor da El, o que é preocupante, pois os } \\
\text { alunos estão sendo incluídos embora não no ritmo desejado. } \\
\text { Coloca-se o ensino itinerante como uma possível maneira } \\
\text { de melhorar a questão da inclusão educacional na realidade } \\
\text { brasileira, assim como o combate aos problemas educacionais } \\
\text { gerais, como o fracasso e evasão escolar. }\end{array}$ \\
\hline $\begin{array}{l}\text { Sobre a El na } \\
\text { formação de } \\
\text { professores } \\
\text { de Ciências: } \\
\text { a tessitura } \\
\text { dos currículos } \\
\text { praticados }\end{array}$ & $\begin{array}{l}\text { Vilela-Ribeiro; } \\
\text { Benite; (2011) }\end{array}$ & $\begin{array}{l}\text { O objetivo foi considerar como está sendo proporcionada a } \\
\text { permanência de todas as pessoas no âmbito universitário e a } \\
\text { preparação dos licenciandos em Ciências para a diversidade. } \\
\text { Foram analisados os Projetos Políticos Curriculares (PPCs) dos } \\
\text { cursos de licenciatura em Ciências de uma Instituição de Ensino } \\
\text { Superior (IES) pública em Jataí, Estado de Goiás, tendo como } \\
\text { foco a noção de El e a maneira como ela está sendo tratada } \\
\text { nesses cursos de formação de professores. Observou-se que } \\
\text { não consta nos documentos pesquisados nenhum tipo de } \\
\text { referência à formação para diversidade. }\end{array}$ \\
\hline $\begin{array}{l}\text { Alfabetização } \\
\text { científica e El } \\
\text { no discurso de } \\
\text { professores } \\
\text { formadores de } \\
\text { professores de } \\
\text { ciências }\end{array}$ & $\begin{array}{l}\text { Vilela-Ribeiro; } \\
\text { Benite (2013) }\end{array}$ & $\begin{array}{c}\text { O objetivo foi analisar concepções a respeito da alfabetização } \\
\text { científica e de temas em El nos discursos de professores } \\
\text { formadores em Ciências, em uma IES em Jataí, Goiás. Foram } \\
\text { realizadas entrevistas que serviram de base para a investigação } \\
\text { das concepções. As concepções docentes percebidas } \\
\text { expressam que a alfabetização científica é fundamental para } \\
\text { os cidadãos e um direito de todos, sem qualquer distinção. } \\
\text { Portanto, subsidiar a formação continuada melhora a formação } \\
\text { em Ciências da Educação Básica quando se refere as práticas } \\
\text { para a El. }\end{array}$ \\
\hline
\end{tabular}




\section{autêntica}

\begin{tabular}{|c|c|c|}
\hline $\begin{array}{c}\text { A formação de } \\
\text { professores para a } \\
\text { El e os possíveis } \\
\text { impactos na } \\
\text { escolarização } \\
\text { de alunos com } \\
\text { deficiências }\end{array}$ & $\begin{array}{l}\text { Kassar } \\
\text { (2014) }\end{array}$ & $\begin{array}{c}\text { Objetivou-se analisar características da formação de professores, } \\
\text { considerando os programas do governo federal do Brasil } \\
\text { para a formação de um sistema educacional inclusivo. Foram } \\
\text { consultados os dados do Censo Escolar do ano de 2012, com } \\
\text { a intenção de conhecer características gerais da formação dos } \\
\text { docentes que atuam na Educação Infantil, Ensino Fundamental e } \\
\text { Ensino Médio. Pareceu que a capacitação para a inclusão ocorre } \\
\text { em instituições privadas ou públicas de modo não presencial } \\
\text { ou por multiplicadores. As análises indicam precariedade } \\
\text { nesses processos, levando-se em conta as características dos } \\
\text { programas formativos e o nível atingido de escolarização dos } \\
\text { alunos com deficiências. }\end{array}$ \\
\hline $\begin{array}{c}\text { A formação de } \\
\text { professores na } \\
\text { perspectiva da El } \\
\text { em Moçambique: } \\
\text { uma perspectiva } \\
\text { crítica }\end{array}$ & $\begin{array}{c}\text { Chambal; } \\
\text { Bueno } \\
\text { (2014) }\end{array}$ & $\begin{array}{l}\text { Objetivou-se analisar a incorporação das políticas de formação } \\
\text { docente pelas instituiçães formativas de professores de } \\
\text { Moçambique, na perspectiva da El. Foram consultados } \\
\text { documentos educacionais oficiais do país, documentos } \\
\text { referentes a organização acadêmica e curricular de cursos } \\
\text { formativos em diferentes níveis e planos e programas } \\
\text { curriculares das disciplinas relacionadas à escolarização de } \\
\text { alunos com deficiências. Constatou-se que existem duas } \\
\text { modalidades de formação correspondente respectivamente } \\
\text { ao ensino médio e superior. Em nível médio não é garantida } \\
\text { a incorporação dos princípios de educação para todos na } \\
\text { perspectiva inclusiva. No nível universitário, constatou-se } \\
\text { diversificação dos cursos oferecidos, mas nenhuma das } \\
\text { disciplinas inclui temas relacionados a inclusão de alunos } \\
\text { com deficiências ou El, deixando tais conteúdos a cargo das } \\
\text { disciplinas específicas. }\end{array}$ \\
\hline $\begin{array}{l}\text { Trajetória da } \\
\text { formação de } \\
\text { professores de } \\
\text { ciências para El } \\
\text { em Goiás, Brasil, } \\
\text { sob a ótica de } \\
\text { participantes } \\
\text { de uma rede } \\
\text { colaborativa }\end{array}$ & $\begin{array}{c}\text { Pereira et. al. } \\
\text { (2015) }\end{array}$ & $\begin{array}{l}\text { O objetivo foi apresentar o contexto da formação de professores } \\
\text { de Ciências no âmbito da El no estado de Goiás e refletir como } \\
\text { o ensino da área contribui na constituição de cidadãos dentro da } \\
\text { escola inclusiva. Realizou-se uma pesquisa participante com } 25 \\
\text { professores estudantes da área da Educação Especial/lnclusiva, } \\
\text { para isso fazendo a discussão de textos divulgados pela } \\
\text { comunidade científica. Constatou-se que nas últimas décadas o } \\
\text { sistema educacional brasileiro tem vivenciado a transição para } \\
\text { a inclusão escolar, mesmo diante das dificuldades enfrentadas, } \\
\text { o que também acontece em Goiás. Entre as dificuldades } \\
\text { percebidas está avançar os modelos de racionalidade técnica de } \\
\text { formação, que ainda regem a formação dos futuros professores. }\end{array}$ \\
\hline
\end{tabular}




\section{autêntica}

DOI https://doi.org/10.31639/rbpfp.v12i24.312

\begin{tabular}{|c|c|c|}
\hline $\begin{array}{c}\text { A formação inicial } \\
\text { de professores } \\
\text { para a educação } \\
\text { in/exclusiva }\end{array}$ & $\begin{array}{c}\text { Bazon } \\
\text { et. al. (2015) }\end{array}$ & $\begin{array}{l}\text { O objetivo foi discutir as perspectivas e desafios dos espaços de } \\
\text { formação inicial para a atuação dos professores na El de pessoas } \\
\text { com deficiências, em sua interface com o Programa Institucional } \\
\text { de Bolsas de Iniciação à Docência. Participaram da pesquisa, por } \\
\text { meio de entrevista semiestruturada, } 96 \text { professores e licenciandos. } \\
\text { Percebeu-se que eles apontam uma formação profissional } \\
\text { desfavorável para a atuação na El; a responsabilidade pela formação } \\
\text { de alunos com deficiências é atribuída a outros profissionais, } \\
\text { pois alega-se despreparo para atendê-los, e os entrevistas não } \\
\text { percebem o seu papel diante da concretização da inclusão. }\end{array}$ \\
\hline $\begin{array}{l}\text { Formação ativa } \\
\text { e expressiva } \\
\text { de professores: } \\
\text { "bagunçando } \\
\text { o coreto" para } \\
\text { estimular a } \\
\text { inclusão! }\end{array}$ & $\begin{array}{l}\text { Lima- } \\
\text { Rodrigues } \\
\text { (2017) }\end{array}$ & $\begin{array}{l}\text { Objetivou-se apresentar uma análise de um curso de formação } \\
\text { continuada e mostrar um exemplo de como potencializar a } \\
\text { mudança de atitudes em favor da Inclusão com ênfase nas } \\
\text { pessoas com deficiências. Foram } 25 \text { horas de curso com } 193 \\
\text { participantes de diversas áreas de ensino, realizadas em cidades } \\
\text { de Portugal. Foram utilizadas atividades diversas para discutir } \\
\text { a inclusão e facilitar a vivência de diferentes experiências, } \\
\text { se colocando, muitas vezes, no lugar do outro para isso. Os } \\
\text { professores ficaram espantados diante de uma nova forma de } \\
\text { aprender, que servirá de base para ensinar a todos. Assim, uma } \\
\text { formação transformadora para a inclusão tem como alicerce } \\
\text { a dimensão pessoal do formando, promovendo a empatia e } \\
\text { retirando as pessoas da zona de conforto por metodologias ativas. }\end{array}$ \\
\hline $\begin{array}{l}\text { A formação do } \\
\text { professor na sala } \\
\text { de aula: atitude } \\
\text { frente à pessoa } \\
\text { com deficiência }\end{array}$ & $\begin{array}{l}\text { Piovesan } \\
\text { et. al.(2019) }\end{array}$ & $\begin{array}{l}\text { Objetivou-se fazer uma revisão sistemática a respeito da formação } \\
\text { de professores para a El no ensino regular, por meio de uma } \\
\text { revisão da literatura. Ela permitiu constatar que a formação para } \\
\text { a área em questão ainda deixa a desejar, porque os docentes se } \\
\text { sentem despreparados para trabalhar no contexto da sala de aula } \\
\text { inclusiva de alunos com deficiências. Por isso, são necessários } \\
\text { programas permanentes que capacitem para a El. }\end{array}$ \\
\hline
\end{tabular}

Fonte: autoras, 2020.

O Quadro 1 apresenta os 9 artigos selecionados na revisão da literatura para a análise, especificando o título, autores, ano de publicação e principais ideias. Ressalta-se que não se teve a pretensão de esgotar as discussões na área da formação de professores para a El de alunos com deficiências, mas de fornecer uma amostra das que têm sido realizadas, as quais indicam que existe preocupação em discutir a formação por esta perspectiva.

Foram percebidas compreensões semelhantes nas discussões, denominadas tendências: a respeito da concepção de El que subsidiou os processos formativos implementados ou as discussões teóricas da formação realizadas; dos objetivos da de formar professores; de como proceder para isso; e de quais as possíveis barreiras a serem transpostas. A seguir são colocadas as discussões de cada uma, dialogando com a literatura da área, para expressar uma compreensão emergente. 


\section{autêntica}

A primeira tendência discutida a partir dos artigos é a concepção de El. Essa concepção norteou os processos de formação e as discussões da temática realizadas. Ela é apontada por Sanchéz (2005) como filosofia educacional, que defende uma educação para todos sustentada na afirmativa de que as escolas, como comunidades educativas, devem satisfazer as necessidades dos alunos, independente das características pessoais, psicológicas ou sociais. Ao contrário do que algumas vezes se enfatiza, ela direciona-se não somente aos alunos com deficiência, que, sem dúvida, têm de continuar sendo contemplados, mas a todo o público atendido pela escola.

Mencionou-se nos artigos o acolhimento de todas as pessoas na escola, sem deixar de enfatizar as pessoas com deficiências (BAZON et al., 2015; VILELA-RIBEIRO; BENITE, 2013; PEREIRA et al., 2015; LIMARODRIGUES, 2017). Em Lima-Rodrigues (2017, p. 717) é preciso "fortalecer a ideia mais ampla de Inclusão, enquanto uma Educação de qualidade e para todos os alunos, de uma escola que não precisa ser "regular" e de uma Educação que não precisa ser "Especial"." Como afirmam Bazon et al. (2015), incluir é muito mais do que disponibilizar atendimento especializado aos alunos com deficiências; se trata de um processo de democratização, de oportunidade de aprendizagem a todos, em um ambiente que historicamente se constituiu como segregado.

Outra possível abordagem para a El contextualiza as pessoas com deficiências (CHAMBAL; BUENO, 2014; KASSAR, 2014; PIOVESAN et. al., 2019). Para Chambal e Bueno (2014), o recorte é importante porque são escassos os registros das políticas de formação docente com foco na inclusão e da permanência de alunos com deficiência na rede pública de ensino. No caso de Kassar (2014) a maior dificuldade está no trabalho inclusivo com esse público. Não quer dizer que os autores desconhecem a ideia de inclusão para todos, mas que optaram por se referir à um público determinado por conta das especificidades de suas pesquisas, o que é comum acontecer (DALL' ACQUA; VITALIANO, 2010).

Diante de cada concepção de El, existem objetivos para a formação inicial e em serviço de professores (segunda tendência analisada). Entre eles, Imbernón (2002) aponta que é pela formação que se pode abandonar a ideia de professor tradicional, enciclopédico ou especialista e técnico, cuja função principal é transmitir conhecimentos acabados. Oportuniza-se o estabelecimento de estratégias de pensamento, a percepção de estímulos e a reflexão da prática pedagógica.

Nos artigos analisados objetivou-se a formação de professores para a valorização das diferenças dos alunos (VILELA-RIBEIRO; BENITE, 2013; LIMA-RODRIGUES, 2017). Para Vilela-Ribeiro e Benite (2013), refletir estes aspectos é uma maneira de criar rupturas para os estereótipos de alunos, previamente estabelecidos nas escolas. Facilita-se a minimização das dificuldades, traçando caminhos metodológicos facilitadores do ensino e aprendizagem de todos, o que é relevante quando se considera que não deve ocorrer desvalorização por conta das diferenças (MANTOAN, 2006).

O processo reflexivo está relacionado com condução de práticas pedagógicas na El e por isso, a reflexão deve ser um objetivo da formação docente (VILELA-RIBEIRO; BENITE, 2011, 2013; LIMA-RODRIGUES, 2017; PEREIRA et. al., 2015; PIOVESAN et. al., 2015). Pereira et al. (2015) e Piovesan et. al. (2019) comentam que é preciso privilegiar o estímulo à reflexão, para a formação de profissionais que articulem um fazer pedagógico comprometido com os direitos dos alunos.

Pelo estímulo à reflexão na formação de professores é possível (re)construir conhecimentos variados na El (outro objetivo) (BAZON, et. al., 2015; PEREIRA et. al., 2015; KASSAR, 2014). Os mesmos, quando assimilados 


\section{autêntica}

DOI https://doi.org/10.31639/rbpfp.v12i24.312

servirão de base para a mediação do processo de ensino e aprendizagem comprometido com a inclusão (BAZON, et. al., 2015). Tais conhecimentos se referem ao que Pimenta (1996) chama de saberes da docência, ou seja, relacionados ao conhecimento científico, que envolvem o próprio conteúdo a ser ensinado, repleto de significados particulares e compartilhados, e aos saberes pedagógicos, representados pela compreensão da didática, do currículo, entre outros.

Com base nos objetivos da El discutidos nos artigos, os autores fizeram proposições de como a formação docente deve ocorrer. Primeiramente, indicou-se que ela seja incluída como componente curricular obrigatório das licenciaturas (PEREIRA et al. 2015, VILELA-RIBEIRO; BENITE, 2011, KASSAR, 2015, BAZON et al, 2015; CHAMBAL; BUENO, 2014; PIOVESAN et. al., 2019). Isso porque os licenciandos quando formados trabalharão na Educação Básica, obrigatoriamente inclusiva (KASSAR, 2015), precisando mediar o processo de ensino de forma a propiciar a aprendizagem a todos. Inclusive, Piovesan (2019) afirma que as licenciaturas precisam ter mais disciplinas transversais e práticas que discutam e capacitem os licenciandos para lidar com alunos com deficiências.

Outra maneira citada para promover a formação para a El foi pelo estabelecimento de parcerias entre profissionais e instituições. De acordo com Pereira et al. (2015) e Bazon et. al. (2015), a criação de redes de formação participada se faz necessária, pois elas facilitam a compreensão da globalidade do sujeito e o entendimento dos processos como dinâmicos e interativos. A troca de experiências e a partilha de saberes configuram espaços mútuos, em que cada um é motivado a desempenhar o seu papel.

Orienta-se ainda, que a formação oferecida aos profissionais do ensino seja contínua e permanente, estando sempre à disposição deles (PIOVESAN, 2019; LIMA-RODRIGUES, 2017). A formação contínua é relevante, pois proporciona o tempo necessário para elaborações que refazem identidades, baseado em pedagogias que consideram as diferenças (PIOVESAN, 2019). Lima-Rodrigues (2017) afirma que desta maneira pode-se tirar as pessoas da zona de conforto e avançar nos pensamentos e ações para a inclusão, por meio de metodologias que facilitam a aprendizagem e dão significados para os conceitos e práticas inclusivas.

Mesmo diante dessas orientações de como formar professores, são ressaltadas na literatura barreiras à concretização da El de pessoas com deficiências que ainda existem, que sugerem que a formação ainda não está acontecendo de maneira efetiva. Parte delas, segundo Pletsch (2009) devem-se ao desafio que representa aos cursos de formação docente, produzir conhecimentos que desencadeiem novas atitudes, que permitam a compreensão de situações complexas de ensino, de forma que aconteça uma atuação profissional responsável e satisfatória atendendo a diversidade.

A primeira barreira à El está na carência de formação docente (BAZON et al., 2015; KASSAR, 2014; CHAMBAL; BUENO, 2014; PIOVESAN et. al., 2019), a qual ressalta a afirmação anterior, de que tais processos não estão acontecendo de maneira satisfatória. Em todo o Brasil destaca-se o despreparo das licenciaturas para a inclusão escolar de alunos com deficiências (BASSO, 2015), o que dificulta o trabalho por esta perspectiva, resultando em prejuízos sociais e acadêmicos a todos os indivíduos (PLETSCH, 2009).

Também, os professores têm conhecimentos limitados, fator identificado nos artigos analisados empecilho à EI (PEREIRA et. al., 2015; VILELA-RIBEIRO; BENITE, 2013; BAZON et. al., 2014). Tal limitação faz com que eles tenham problemas em construir novas representações acerca dos alunos com deficiência e mantenham ideias preconceituosas e segregacionistas (BAZON, et. al., 2014). Por causa dessa insuficiência de conhecimentos alguns docentes se posicionem contra a inclusão escolar e atribuam essa função para profissionais de apoio (VILELA-RIBEIRO; BENITE, 2013). 


\section{autêntica}

Outra condição que se torna uma barreira é a falta de infraestruturas adequadas, entendidas como as instalações que colaboram com o desenvolvimento das atividades escolares - sala de aula, administração, banheiros, cozinha, biblioteca, em que existem iluminação, climatização, mobiliário específico. Tratam-se de elementos que garantem a remoção de barreiras de um determinado espaço para que todos tenham acesso a ele (LOPES; CAPELLINI, 2015). Para Vilela-Ribeiro e Benite (2013) e Pereira et. al. (2015) os espaços educacionais precisam estar adaptados para incluir todas as pessoas.

A falta de incentivos administrativos e políticos se tornam outra dificuldade na concretização da El. Para Vilela-Ribeiro e Benite (2013) as iniciativas políticas e institucionais são importantes, tendo em vista que sem política de qualificação profissional nas instituições de ensino superior, dificulta-se que os profissionais busquem formação por iniciativa própria. Kassar (2015) aponta que as características das políticas de ensino superior e das relacionadas à formação docente para a El, quando pouco consistentes, contribuem para ressaltar os desafios existentes. De acordo com Piovesan et. al. (2019) para a efetivação de mudanças sociais, a sociedade deve ser responsabilizada a partir da conscientização nos serviços públicos e privados, a respeito das potencialidades das pessoas com deficiências para que se valorize a diversidade humana.

A partir da superação das dificuldades existentes na área que foram discutidas, as pesquisas desenvolvidas apontam caminhos que têm contribuído par a promoção da El. Também, incentivam o pensamento de estratégias que condigam com as exigências da El de alunos com deficiências. Para os professores, isso repercute em ações como: maior domínio dos conteúdos científicos e conhecimentos pedagógicos; embasamento das práticas na reflexão; planejamentos coerentes; desenvolvimento e avaliações que considerem o cotidiano da sala de aula como objeto de investigação e articulação da teoria e da prática. Acima de tudo, esta é uma possibilidade de reduzir o preconceito por parte dos integrantes da escola com os alunos com deficiências, partindo de potencialidades e não de limitações. 


\section{autêntica}

\section{Considerações finais}

Esta pesquisa questionou: como estão sendo discutidos os processos de formação inicial e em serviço de professores voltados à El de pessoas com deficiências? O objetivo principal foi compreender com base na literatura, como estão sendo realizadas as discussões da formação dos referidos profissionais dentro da temática. Os resultados obtidos a partir das especificações propostas e as argumentações realizadas, responderam ao problema.

As discussões feitas pelos autores das pesquisas investigadas aconteceram com base em argumentos teóricos sólidos originados na literatura e/ou em experiências aplicadas, que fizeram emergir tendências principais, referentes à concepção de $\mathrm{El}$, aos objetivos de formar professores, de como proceder para isso, e de quais as possíveis barreiras encontradas. Procurou-se expressar pontos de vista em favor da inclusão e da preparação profissional para isso.

Existe o reconhecimento do papel que os docentes assumem e das exigências para um ensino e aprendizagem comprometido com a El de pessoas com deficiências, cuja concretização se constitui no maior objetivo identificado para os processos formativos. Indica-se que tais processos aconteçam como componente curricular obrigatório e por meio de parcerias entre instituições e pessoas; o interesse em participar deve partir dos sujeitos, mas também são necessários incentivos governamentais e institucionais para isso. As principais barreiras identificadas referem-se à negação da inclusão, à falta de conhecimento, aos processos formativos insuficientes, às infraestruturas inclusivas serem inadequadas e a falta de incentivos administrativos e políticos.

Ficou claro que o caminho a percorrer é longo para que os professores estejam adequadamente formados para atuação na El, com isso, facilitem a inclusão dos alunos com deficiências nas escolas. Além disso, a formação docente qualificada pode muito, mas não pode tudo. Outros aspectos configuram os sistemas de ensino, como as condições de trabalho na educação, o aprimoramento do sistema de gestão, a conscientização da sociedade dos direitos das pessoas com deficiência e assim por diante. Um trabalho considerando esses aspectos junto com a formação docente é potencial na construção de uma sociedade mais igualitária. Não se espera que toda uma cultura de segregação e discriminação, de atribuição de responsabilidades aos professores especialistas em Educação Especial, seja deixada de lado do dia para a noite.

Assim, propostas futuras de continuação dessa pesquisa consistem em implementar um curso de formação docente em nível inicial tematizando a El de pessoas com deficiências. Da mesma forma que a teoria, a prática se faz essencial para a promoção das mudanças que se esperam na sociedade, especialmente para a concretização de uma educação para todos. 


\section{autêntica}

DOI https://doi.org/10.31639/rbpfp.v12i24.312

\section{Referências}

AINSCOW, Mel. Tornar a educação inclusiva: Como essa tarefa deve ser conceituada? IN: Tornar a educação inclusiva / organizado por Osmar Fávero, Windyz Ferreira, Timothy Ireland e Débora Barreiros. - Brasília: UNESCO, 2009.

BASSO, Sabrina Pereira Soares. Cursos de licenciatura na área de ciências: a temática inclusão escolar de alunos com necessidades educacionais especiais. 2015. 130 f. Tese (Doutorado) - Curso de Programa de Pósgraduação em Educação Para A Ciência, Universidade Estadual Paulista "Júlio de Mesquita Filho," Bauru, 2015. Disponível em: <https://repositorio.unesp.br/bitstream/handle/11449/135946/000859076. pdf? sequence=1>. Acesso em: 22 jan. 2019.

BAZON, Fernanda Vilhena Mafra et al. A formação inicial de professores para a educação in/exclusiva. Revista Educação e Cultura Contemporânea, v. 13, n. 30, p. 130-156, 2015.

BRASIL, Ministério da Educação e Cultura. Política Nacional de Educação Especial na Perspectiva da Educação Inclusiva. 2008. Disponível em: 『http://portal.mec.gov.br/docman/dezembro-2014-pdf/16690-politica-nacional-de-educacao-especial-na-perspectiva-da-educacao-inclusiva-05122014. Acesso em 23 de mar. 2020

CHAMBAL, Luís Alfredo; BUENO, José Geraldo Silveira. A formação de professores na perspectiva da educação inclusiva em Moçambique: uma perspectiva crítica. Cadernos CEDES, v. 34, 2014.

ESCUDERO, Juan M.; MARTÍNEZ, Begoña. Educación inclusiva y cambio escolar. Revista iberoamericana de educación, v. 55, p. 85-105, 2011.

FERREIRA, Windyz B. Entendendo a discriminação contra estudantes com deficiência na escola. IN: Tornar a educação inclusiva / organizado por Osmar Fávero, Windyz Ferreira, Timothy Ireland e Débora Barreiros. Brasília: UNESCO, 2009

GIL, Antonio Carlos. Como elaborar projetos de pesquisa. 3. ed. São Paulo: Atlas, 2002.

HEREDERO, Eladio Sebastian. A escola inclusiva e estratégias para fazer frente a ela: as adaptações curriculares. Acta Scientiarum. Education, v. 32, n. 2, 2010, p. 193-208.

IMBERNÓN, Francisco. Formação docente e profissional: formar-se para a mudança e a incerteza. 3. ed. São Paulo: Cortez, 2002.

KASSAR, Mônica de Carvalho Magalhães. A formação de professores para a educação inclusiva e os possíveis impactos na escolarização de alunos com deficiências. Cadernos CEDES, Campinas, v. 34, n. 93, p. 207-224, 2014.

LOPES, Jéssica Fernanda; CAPELLINI, Vera Lúcia Messias Fialho. Escola Inclusiva: um estudo sobre a infraestrutura escolar e a interação entre os alunos com e sem deficiência. Cadernos de Pesquisa em Educação, v. 20, n. 42, 2015.

MANTOAN, Maria Eglér. Igualdade e diferenças na escola: como andar no fio da navalha. In: ARANTES, Valéria Amorim (Org.). Inclusão escolar: Pontos e Contrapontos. São Paulo: Summus, 2006. p. 15-29. 
MINETTO, Maria de Fátima. Currículo na educação inclusiva: entendendo esse desafio. 2. ed. Curitiba: Ibpex, 2008. $135 \mathrm{p}$.

NÓVOA, António. Formação de professores e profissão docente. In: NÓVOA, António. Os professores e sua formação. Lisboa: Instituto de Inovação Educacional, p.139-158, 1992.

NUNES, Camila Almada. A formação continuada do docente para atuar na perspectiva da inclusão: a busca de contribuições para a prática pedagógica do professor da escola regular. 2014. 162 f. Dissertação (Mestrado) - Curso de Programa de Pós-graduação em Educação, Universidade Estadual do Ceará, Fortaleza, 2014

PEREIRA, Lidiane de Lemos Soares et al. Trajetória da formação de professores de ciências para educação inclusiva em Goiás, Brasil, sob a ótica de participantes de uma rede colaborativa. Ciência \& Educação, v. 21, n. 2, p. 473-491, 2015.

PIMENTA, Selma Garrido. Formação de professores: saberes da docência e identidade do professor. Revista da Faculdade de Educação, v. 22, n. 2, p. 72-89, 1996.

PIOVESAN, Josiane Bertoldo et. al. A formação do professor na sala de aula: atitude frente à pessoa com deficiência. Revista Educação, Artes e Inclusão, v. 15, n. 4, 2019, p. 230-250.

PLETSCH, Márcia Denise. A formação de professores para a educação inclusiva: legislação, diretrizes políticas e resultados de pesquisa. Educar em Revista, v. 25, n. 33, p. 143-156, 2009.

PRIETO, Rosângela Gavioli. Atendimento escolar de alunos com necessidades educacionais especiais: um olhar sobre as políticas de educação no Brasil. In: ARANTES, Valéria Amorim (Org.). Inclusão Escolar: pontos e contrapontos. São Paulo: Summus, 2006. Cap. 3. p. 31-69.

RODRIGUES, David. Educação inclusiva: mais qualidade à diversidade. In: RODRIGUES, David; KREBS, Ruy; FREITAS, Soraia Napoleão (Org.). Educação Inclusiva e Necessidades Educacionais Especiais. Santa Maria: Editora UFSM, 2005. Cap. 2. p. 45-64.

SOUZA, Márcia Cristina de. Contextos educacionais inclusivos de alunos surdos: ações frente à realidade inclusiva de professores de matemática da educação básica. 2013. 2012 f. Tese (Doutorado) - Curso de Programa de Pós-graduação, em Ensino de Ciências e Educação Matemática, Universidade Estadual de Londrina, Londrina, 2013.

VILELA-RIBEIRO, Eveline Borges; BENITE, Anna Maria Canavarro. Alfabetização científica e educação inclusiva no discurso de professores formadores de professores de ciências. Ciência \& Educação, v. 19, n. 3, p. 781-794, 2013.

VILELA-RIBEIRO, Eveline Borges; BENITE, Anna Maria Canavarro. Sobre a educação inclusiva na formação de professores de Ciências: a tessitura dos currículos praticados. Acta Scientiarum, v. 33, n. 2, p. 239-245, 2011.

VITALIANO, C. R; VALENTE, Silvia Maria Pasello. A formação de professores reflexivos como condição necessária para inclusão de alunos com necessidades educacionais especiais. In: Formação de professores para inclusão de alunos com Necessidades Educacionais Especiais. Célia Regina Vitaliano (Org.). Londrina: Eduel, 2010, p. 22-38. 
